\title{
PSICOPATIA E A APLICAÇÃO DA PENA
}

\section{PSYCHOPATHY AND THE APPLICATION OF THE PENALTY}

\author{
Yasmin Cipione Capucio de Almeida ${ }^{1}$, Alexander Corrêa Albino da Silva ${ }^{2}$ \\ ${ }^{1}$ Graduanda do Curso de Direito da Faculdade Raízes - yasmincapucio3@gmail.com \\ ${ }^{2}$ Professor Especialista Alexander Corrêa Albino da Silva - alexadvocatus@gmail.com
}

\begin{abstract}
Resumo: A psicopatia é um tema que desde o início dos tempos desafia todas as áreas científicas que a envolve, no que diz respeito ao conceito, características, tratamento, bem como sob a aplicação da pena. O presente trabalho se dedica ante as limitações existentes, identificar qual o meio de pena devem ser aplicadas ao psicopata, com base nos conceitos, pensamentos, características, e tantas outras teorias que serão apresentadas.
\end{abstract}

Palavras-chave: Psicopatia; Doença mental; Crime; Pena.

Abstract: Psychopathy is a topic that from the beginning of time defies all the scientific areas that involves it, with regard to concept, characteristics, treatment as well as under the application of the penalty. The present work is dedicated to the existing limitations, to identify which means of punishment should be applied to the psychopath, based on the concepts, thoughts, characteristics, and many other theories that will be presented.

Keywords: Psicopatia; Mental disease; Crime; Feather.

\section{INTRODUÇÃO}

De acordo com o exposto no livro "Sem Consciência" de Robert D. Hare (2013, p. 199), ao final de todos os meios de estudos de tratamento do distúrbio de psicopatia, a conclusão é a mesma, de que ainda não foi identificado um tratamento efetivo e que os já testados não possuem eficácia.

A legislação brasileira atual prevê alguns tipos de punições, sendo a pena privativa de liberdade e/ou de direito, medida de segurança e interdição. Se formos olhar sob a órbita de um crime praticado por um psicopata, qual o meio de punição correto, a sua eficácia, sua duração, tal medida é colocada em prática em nosso país?

1. CRIME, CULPABILIDADE INIMPUTABILIDADE

1.1. Crime (fato típico e
antijurídico)

Pelo fato de vivermos em sociedade desde o princípio do tempo, fez-se necessário a criação de normas jurídicas, as quais possuíam a função de prevenir os abusos por parte das autoridades, bem como proteger os bens jurídicos de maior importância.

As normas jurídicas são adequadas de acordo com a evolução da sociedade e daqueles que nela convivem, contudo, sem deixar de lado o seu objetivo, qual seja de criminalizar condutas e impor penas para aqueles que as transgredem.

O conceito analítico de crime se subdivide em formal e material, o aspecto formal dita que é considerado crime todas as ações ou omissões proibidas por lei, sob ameaça aplicação E de pena, enquanto o segundo aspecto falará que é considerado crime todas as ações ou omissões que opor-se aos valores da sociedade, a qual é proibida sob a ameaça de pena. 
A Lei de Introdução do Código Penal tratará no seu artigo primeiro o conceito de crime, veja-se:

“Art. $1^{\circ}$ Considera-se
crime a infração penal a
que a lei comina pena de
reclusão ou de detenção,
quer isoladamente, quer
alternativa ou
cumulativamente com a
pena de multa;
contravenção, a infração
penal a que a lei comina,
isoladamente, penas de
prisão simples ou de
multa, ou ambas,
alternativa ou
cumulativamente".

Diante disso, é cediço que para que haja a configuração de crime se faz necessária a presença indispensável de 03 (três) elementos estruturais, quais sejam: a tipicidade, ilicitude e culpabilidade.

A tipicidade tratará do caráter externo da ação praticada pelo acusado, observará apenas o comportamento humano que terá um resultado expressamente proibido em lei; a antijuridicidade ocorrerá quando o comportamento descrito em lei penal incriminadora não for expressamente lícito; já a culpabilidade levará em consideração o aspecto subjetivo do crime, ou seja, a reprovabilidade da ação praticada pelo acusado.

Assim, a ausência de qualquer um desses elementos estruturais, fará com que não reste configurada a conduta delituosa.

\subsection{Culpabilidade}

Para a aplicação da pena, bem como para a caracterização do crime deverá ser levado em consideração à culpabilidade do agente, que em síntese é a reprovabilidade da ação ou omissão praticada.

Veja-se o que o autor CAPEZ (2017, p. 317) nos diz sobre o tema:

"[...] quando se diz que "Fulano" foi o grande culpado pelo fracasso de sua equipe ou de sua empresa, está atribuindose-lhe um conceito negativo de reprovação. A culpabilidade exatamente isso, ou seja, a possibilidade de se considerar alguém culpado pela prática de uma infração penal. Por essa razão, costuma ser definida como juízo de censurabilidade e reprovação exercido sobre alguém que praticou um fato típico e ilícito".

Outrossim, a culpabilidade nada mais é do que o grau negativo que se extrai do fato típico e ilícito praticado pelo agente.

A lei preleciona as causas que excluem e diminuem a culpabilidade do agente. Em primeiro lugar temos a imputabilidade, que é a capacidade que o agente possui de ser responsável penalmente pelos seus atos, sendo esses típicos e antijurídicos. A ausência dessa capacidade ou 
alteração psíquica que diminua a maturidade do agente faz com que o mesmo se torne inimputável.

O Código Penal Brasileiro trata no caput do artigo 26 sobre a isenção de pena do inimputável e em seu parágrafo único sobre a diminuição da pena para os agentes com perturbação da saúde mental ou desenvolvimento mental incompleto ou retardado.

Também serão considerados inimputáveis os menores de dezoito anos de idade, conforme preleciona o artigo 228 da Constituição Federal e o artigo 27 do Código Penal, respectivamente apresentados abaixo:

“Art. 228. São penalmente inimputáveis os menores de dezoito anos, sujeitos às normas da legislação especial.

Art. 27 - Os menores de 18 (dezoito) anos são penalmente inimputáveis, ficando sujeitos às normas estabelecidas na legislação especial”.

Será considerado inimputável, assim como os casos supramencionados, o agente quando for incapaz de conhecer e autodeterminarse de acordo com o seu entendimento. Enquadrase nesse aspecto os agentes que sofrem de perturbação mental ou possuem desenvolvimento mental incompleto ou retardado, os quais terão a pena diminuída, conforme expõe o artigo 26, parágrafo único, do Código Penal:

"Parágrafo único - A pena

pode ser reduzida de um a dois terços, se o agente, em virtude de perturbação de saúde mental ou por desenvolvimento mental incompleto ou retardado não era inteiramente capaz de entender o caráter ilícito do fato ou de determinar-se de acordo com esse entendimento".

Igualmente, o Código Penal nos fala ainda que serão isentos ou terão sua pena diminuída, o agente que no momento do fato estava em estado de embriaguez, proveniente de caso fortuito ou força maior, bem como nos casos em que o agente não possua condição de mensurar o injusto do fato praticado pelo mesmo.

No mesmo sentido, ocorrerá a exclusão da culpabilidade nos casos de inexistência da possibilidade de conhecimento do caráter ilícito da conduta praticada, no caso de coação moral irresistível e de obediência hierárquica, não manifestamente ilegal.

\subsubsection{Elementos}

da

culpabilidade

A culpabilidade é um juízo de reprovação social, que incidirá sobre o agente e o fato praticado, o qual deve ser imputável no momento do fato, atuar com consciência potencial de ilicitude, bem como possuir a possibilidade de atuar de outra forma, sendo essa licita.

Assim, para a caracterização da culpabilidade é necessário estar presente todos os seus elementos, bastando à ausência de apenas um para ocorrer a sua desclassificação. 
Em primeiro lugar deve ser observada a capacidade psíquica do agente, se o mesmo possui total capacidade de entendimento diante da antijuridicidade de sua conduta, tal como a sua compreensão, e senão qual o seu grau de consciência. Esse primeiro elemento visa analisar a capacidade do agente de responder penalmente pelo seu ato ilícito praticado, ou seja, sua sanidade mental, sendo denominada de imputabilidade.

Sobre a imputabilidade leciona MIRABETE (2009, p. 196) que:

"Há imputabilidade quando o sujeito é capaz de compreender a ilicitude de sua conduta e de agir de acordo com esse entendimento. ${ }^{34}$ Só é reprovável a conduta se o sujeito tem certo grau de capacidade psíquica que lhe permita compreender a antijuridicidade do fato e também a de adequar essa conduta a sua consciência. Quem não tem essa capacidade de entendimento e de determinação é inimputável, eliminandose a culpabilidade".

No entanto, não basta à verificação somente da imputabilidade para que a conduta seja considerada reprovável, tendo que ser verificado ainda o potencial de consciência da ilicitude e a exigibilidade da conduta diversa.
O potencial de consciência da ilicitude, também chamada de possibilidade de conhecimento da antijuridicidade do fato, é o meio usado para que o agente possa tomar conhecimento de que o seu ato praticado é juridicamente proibido e contrário às normas que regem a convivência em sociedade. Deve ser apurado também se o agente possuía no momento do ato consciência da sua ilicitude e se poderia ter praticado outro ato permitido por lei, no lugar do ato ilícito.

A consciência da ilicitude pode ser apenas razoável, não havendo necessidade que o agente tenha conhecimento técnico-jurídico sobre as proibições contidas no ordenamento jurídico.

O terceiro e último elemento, conhecido como exigibilidade de conduta diversa, como o próprio nome diz, deve ser analisado se no momento do fato era possível exigir do agente um comportamento diverso ao praticado (fato típico e antijurídico), ou se existe algum motivo ou circunstância pessoal que faça com que não permita conduta diversa.

Nesse sentido, só é possível verificar a culpabilidade se o agente possuir condição psíquica para sofrer aplicação de pena, se no momento do fato era capaz de compreender a ilicitude do seu ato e se na circunstância dos fatos era possível exigir do mesmo, conduta diversa da praticada.

\subsection{Imputabilidade}

Como já tratado, a imputabilidade é o conjunto de condições pessoas que o agente possui de entender o caráter ilícito do fato praticado, ou seja, a sanidade mental e a maturidade, bem como ter total condição de controlar sua vontade. 
Será considerado inimputável o agente que não possuir sanidade mental ou possuir falta de maturidade mental no momento da conduta proíba por lei, devido a sua incapacidade de culpabilidade. Nesse sentido, não será possível a aplicação de pena ao agente, ou caso haja essa possibilidade poderá ter a pena diminuída, assim como mencionado anteriormente nos casos de exclusão e diminuição da culpabilidade.

Atualmente possui três sistemas que podem ser utilizados para verificar se o agente é inimputável, sendo os seguintes critéios: biológico, psicológico e o biopsicológico.

O Brasil adota o critério biopsicológico, o qual é uma mescla dos critérios supramencionados, nesse sentido será considerado inimputável o agente que no tempo da ação ou omissão possuía anomalia mental, que faz com que o mesmo não possua capacidade de compreender a ilicitude de sua conduta ou de determinar-se de acordo com essa apreciação.

As causas de inimputabilidade possuem rol taxativo presente no Código Penal, não permitindo interpretação extensiva em prejuízo do réu. Aind sob o estudo em questão se faz necessário analisar a caracterização da inimputabilidade em decorrência de doença mental.

A expressão “doença mental” deve ser analisada sob uma ótica ampla, a qual deve englobar os problemas patológicos, enquadrando todos os tipos de doença mental independente se essa é transitória ou permanente, tendo que ser levado em consideração à capacidade de entendimento, maturidade do agente, e aquelas que são de origens toxicológicas.
NUCCI (2017, p. 513) nos dá alguns exemplos de doença mental, veja-se:

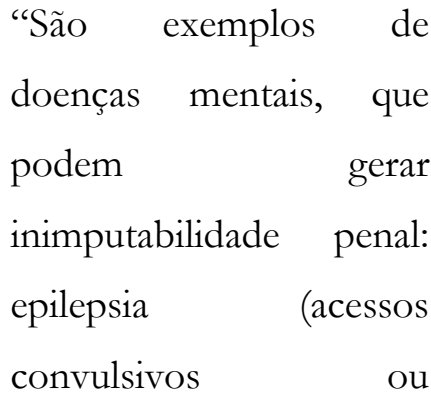

fenômenos puramente cerebrais, com diminuição da consciência, quando o enfermo realiza ações criminosas automáticas; a diminuição da consciência chama-se "estado crepuscular"); histeria (desagregação da consciência, $\quad$ com impedimento ao desenvolvimento de concepções próprias, terminando por falsear a verdade, mentindo, caluniando e agindo por impulso); neurastenia (fadiga de caráter psíquico, com manifesta irritabilidade e alteração de humor); psicose maníaco-depressiva (vida desregrada, mudando humor e caráter alternativamente, tornand o-se capaz de ações cruéis, com detrimento patente das emoções); melancolia 
(doença dos sentimentos, que faz o enfermo olvidar a própria personalidade, os negócios, a família e as amizades); paranoia (doença de manifestações multiformes, normalmente composta por um delírio de perseguição, sendo primordialmente intelectual; pode matar acreditando estar em legítima defesa); alcoolismo (doença que termina por rebaixar a personalidade, com frequentes ilusões $\mathrm{e}$ delírios de perseguição); esquizofrenia (perda do senso de realidade, havendo nítida apatia, com constante

isolamento; perde-se o elemento afetivo, existindo introspecção; não diferencia realidade $\mathrm{e}$ fantasia); demência (estado de enfraquecimento mental, impossível de remediar, que desagrega a personalidade); psicose carcerária (a mudança de ambiente faz surgir uma espécie de psicose); senilidade (modalidade de psicose, surgida na velhice, com progressivo empobrecimento intelectual, ideias delirantes e alucinações)".

\section{A PSICOPATIA}

\subsection{Conceito de psicopatia}

O termo "psicopatia" vem do grego, psyche que significa mente e pathos doença, também é reconhecida como transtorno de personalidade antissocial ou dissocial. O conceito de psicopatia não é um tema pacificado entre os especialistas da área da psiquiatria ou psicologia, contudo, a corrente conservadora considera a psicopatia como uma doença mental, tal como diz o sentido etimológico da palavra.

Em 1941, o psiquiatra Hervey M. Cleckley (1903 - 1984) foi um dos primeiros estudiosos a tornar efetivo o conceito de psicopatia e o seu termo, em sua obra The Mask of Sanity (A Mascará da Sanidade), na qual descreve as características da psicopatia que se totalizavam em 16, veja-se:

"(1) charme superficial e boa inteligência, ausência de delírios e outros sinais de pensamento irracional, (3) ausência de nervosismo, (4) não confiável, falsidade e falta de sinceridade, (6) ausência de remorso ou vergonha, comportamento antissocial 
inadequadamente

motivado, (8) julgamento

deficitário e falha em aprender com a

experiência,

egocentrismo patológico

e incapacidade de amar,

(10) deficiência geral nas reações

afetivas

principais,

(11) perda

especifica de insight, (12)

falta de resposta nas

relaciones interpessoais

gerais,

comportamento

fantástico e desagradável com bebida e, às vezes, sem, (14) suicídio raramente concretizado, (15) vida sexual e interpessoal trivial $\mathrm{e}$ deficitariamente integrada e (16) fracasso em seguir um plano de vida".

O psicólogo, professor e pesquisador canadense Robert Hare após muitos estudos e com base nas características desenvolvidas por Clackley, explorou o tema e criou um método amplamente utilizado, o Psychopathy Checklist (PCL) e o atual Psychopathy Checklist-Revised (PCL-R), o qual possui seus itens baseados nas características formuladas por Clackley, sendo eles: charme superficial; senso grandioso de autoestima; mentira patológica; ausência de remorso ou culpa; afeto superficial; crueldade; comportamento sexual promíscuo; falta de objetivos realistas de longo prazo; impulsividade; irresponsabilidade; falha em aceitar responsabilidade pelas próprias ações; versatilidade criminal; necessidade de estimulação; ludibriador/manipulador; estilo de vida parasita; controle deficiente do comportamento; problemas comportamentais precoces; muitas relações conjugais de curta duração; delinquência juvenil; e revogação da liberação condicional.

Para que haja o diagnostico da psicopatia, o paciente deve ter no mínimo 18 (dezoito) anos de idade, devendo já ter apresentado alguns sintomas desse transtorno antes dos 15 (quinze) anos, o qual deve persistir até a vida adulta.

O transtorno de psicopatia é comum entre familiares biológico, no entanto, quando advém de familiares biológicos femininos o risco é maior se comparado com o biológico masculino. Em uma família em que uma pessoa apresenta o transtorno de personalidade antissocial, os indivíduos do sexo masculino tem mais probabilidade de ter o transtorno de personalidade antissocial e por uso de substância, enquanto que os de sexo feminino apresentam na maioria das vezes apresentam transtorno de sintomas somáticos.

O CID-10 (Classificação Internacional de Doenças) define a personalidade dissocial sob o código F60.2, como:

“Transtorno de personalidade caracterizado por um desprezo das obrigações sociais, falta de empatia para com os outros”. Há um desvio considerável 
entre o comportamento e

as normas sociais

estabelecidas.

comportamento não é

facilmente modificado

pelas experiências

adversas, inclusive pelas

punições. Existe uma

baixa tolerância à

frustração e um baixo

limiar de descarga da

agressividade, inclusive da

violência. Existe uma

tendência a culpar os

outros ou a fornecer

racionalizações plausíveis

para explicar um

comportamento que leva

o sujeito a entrar em

conflito com a sociedade.

Personalidade (transtorno

da):

- amoral;

- anti-social;

- associal;

- psicopática;

- sociopática".

Os critérios apresentados pelo Manual de Diagnóstico e Estatística das Perturbações Mentais (DSM) são os seguintes:

"Agressão a Pessoas e

\section{Animais}

1. Frequentemente

provoca, ameaça ou

intimida outros.
2. Frequentemente inicia brigas físicas.

3. Usou alguma arma que pode causar danos físicos graves a outros (p. ex., bastão, tijolo, garrafa quebrada, faca, arma de fogo).

4. Foi fisicamente cruel com pessoas.

5. Foi fisicamente cruel com animais.

6. Roubou durante o confronto com uma vítima (p. ex., assalto, roubo de bolsa, extorsão, roubo à mão armada).

7. Forçou alguém a atividade sexual.

Destruição de

\section{Propriedade}

8.

Envolveu-se

deliberadamente na provocação de incêndios com a intenção de causar danos graves.

9.

Destruiu

deliberadamente

propriedade de outras pessoas

(excluindo provocação de incêndios).

Falsidade ou Furto

10. Invadiu a casa, o edifício ou o carro de outra pessoa. 
11. Frequentemente mente para obter bens materiais ou favores ou para evitar obrigações (i.e., "trapaceia").

12. Furtou itens de valores consideráveis sem confrontar a vítima (p. ex., furto em lojas, mas sem invadir ou forçar a entrada; falsificação).

Violações Graves de

\section{Regras}

13. Frequentemente fica fora de casa à noite, apesar da proibição dos pais, com início antes dos 13 anos de idade.

\section{Fugiu de casa,} passando a noite fora, pelo menos duas vezes enquanto morando com os pais ou em lar substituto, ou uma vez sem retomar por um longo período.

15. Com frequência falta às aulas, com início antes dos 13 anos de idade".

Os indivíduos que são diagnosticados com psicopatia não são necessariamente assassinos, traficantes ou algum tipo de infratores penais.

Segundo o escritor Hare (2013) não são todos os delinquentes portadores de psicopatia, porém os que possuem cometem crime, possui menos probabilidade de ser por consequência da sua condição social, mas sim decorrem do seu caráter, que não tem como referência as regras, nem tampouco os regulamentos da sociedade. Porém, ao contrario da grande parte dos criminosos, os psicopatas não possuem lealdade a nenhum tipo de grupo, com exceção de quando cuidam da única pessoa que importa para o mesmo.

Hare (2013, p. 98), diz mais no que diz respeito ao caráter criminoso do psicopata, vejamos:

"Em muitos aspectos, é difícil imaginar como algum psicopata - com a falta de controle interno, atitudes incomuns em relação à ética e à moral, a visão de mundo frio, egocêntrica e sem remorso, etc. - pode não entrar em conflito com a sociedade em algum momento de sua vida. A grande maioria entra, é claro, e suas atividades criminosas abrangem todo o conjunto de possibilidades, desde pequenos furtos $\mathrm{e}$ desfalques até assalto, extorsão e roubo à mão armada; desde vandalismo e perturbação da paz até sequestro, assassinato e crimes contra o Estado, 
como traição de segredos da pátria, espionagem e terrorismo".

No entanto, entende-se que o simples fato do psicopata possuir uma estrutura da personalidade diferenciada e com grandes reflexos de maldade, basta para ser visto como um problema para o resto da humanidade.

Alguns autores subdividem a psicopatia em dois graus, sendo o grau leve e o grau moderado a grave. Entende-se que a maioria das pessoas que possuem esse transtorno em grau leve, são aqueles que estão em nossa volta sem ser notados, os quais que para ser diagnosticado a uma dificuldade maior, devido não preencher todos os critérios apresentados pelo DSM.

$\mathrm{O}$ indivíduo que possui esse transtorno em grau moderado a grave são aqueles que se enquadram nos critérios apresentados pelo DSM, além de possuir todas as características destacadas acima no que se refere ao grau leve, contudo, essas serão apresentadas de forma mais extrema. Essa pessoa pode não deixar claro para os outros em sua volta a sua personalidade, porém há uma grande probabilidade de se envolverem com drogas, álcool, tráfico, jogos compulsivos, vandalismo e outros atos ilícitos.

No que diz respeito à cura ou tratamento do transtorno de psicopatia, lamentavelmente, segundo Robert D. Hare (2013, p. 194) ao final de todas as revisões acadêmicas da literatura disponível as conclusões são as mesmas, de que não há nenhum tratamento efetivo descoberto, nem tampouco algo tenha funcionado totalmente.
A psicopatia para a medicina ainda é considerada um grande mistério, vez que até o presente momento não foi possível desenvolver um método totalmente eficaz para o seu tratamento.

\section{APLICAÇÃO DA PENA AOS PORTADORES DE PSICOPATIA}

\subsection{Origem da pena}

Não há relatos precisos que comprem quando começaram a utilizar a pena, contudo, o pouco que se sabe indica que a pena existe como meio de punição desde as comunidades primitivas, as quais eram usadas para punir aqueles que não cumprissem as ordens dos clãs.

Com o passar do tempo os meios utilizados para punir foram sofrendo mudanças e ajustes, passando a serem reguladas pelas legislações penais marcadas pela natureza religiosa, justificando-se em fundamentos religiosos.

Durante o tempo da antiguidade, Platão (427 - 347 a.C.) pronunciava que a lei tinha origem divina e a justiça era a força da harmonia entre as virtudes da alma, possuindo como fim o respeito à lei.

Já na idade média as autoridades representavam a vontade divina e não permitiam que os acusados se defendessem no que diz respeito a pena, os quais tinham que caminhar sobre o fogo ou mergulhar em água fervendo com o intuito único de provar sua inocência.

Assim as modificações persistiram até a presente data, atualmente as sanções são impostas pelo Estado, por meio de ação penal, como sendo consequência ao criminoso pelo fato de ter cometido crime e como forma de prevenção contra novas praticas delitivas. 
Nucci (2017, p. 622) leciona fundamentos primordiais para a existência da pena: “a) denúncia: fazendo com que a sociedade desaprove a prática do crime; b) dissuasão: desaconselhando as pessoas de modo geral e, particularmente, o próprio criminoso à prática delitiva;

\section{c) incapacitação:}

protegendo a sociedade do criminoso, retirando-o de circulação;

d) reabilitação: reeducando o ofensor da lei penal; e) reparação: trazendo alguma recompensa ̀̀ vítima; f) retribuição: dando ao condenado uma pena proporcional ao delito cometido".

A pena não é vista apenas como consequência pela pratica do crime por um agente, possui também carater preventivo o qual se desdobra em dois, o geral e o especial, subdividindo ambos em positivo e negativo.

O carater da pena preventiva geral postitiva significa o poder intimidativo que representa a todos da sociedade, destinatária da norma penal; o geral negativo reafirma a existência e a eficiência do direito penal; o carater especial positivo tem a proposição de ressocializar o acusado condenado, para que possuia condições de conviver novamente em sociedade após o cumprimento da pena ou recebimento do benefício, quando consedido; por último o carater especial negativo significa a intimidação do autor do fato ilícito para que não volte a praticar novos atos proibidos por lei, imputando-lhe prisão quando necessário.

\subsection{Espécies de pena.}

No ordenamento jurídico brasileiro há as seguintes espécies de penas: privativas de liberdade, restritivas de direitos e pecuniárias, também denominada de multa.

As penas privativas de liberdades acolhe a pena de reclusão, detenção e prisão simples. A reclusão admite o regime fechado, semiaberto e aberto, a qual se entende que em regra deve ser aplicada a infrações mais graves, pelo fato de comportar maior restrição a direitos. Quanto à detenção, aceita o regime semiaberto e o aberto, contudo, admitirá o fechado caso haja necessidade de transferência para tal regime, conhecido como regressão de regime.

No que diz respeito à prisão simples, está prevista na Lei das Contravenções Penais que informa que serão aplicadas a infrações penais menores lesividades, ou seja, contravenções. Quanto ao cumprimento é necessário observar o disposto no artigo $6^{\circ}$ da lei supramencionada, vejase:

"Art. $6^{\circ} \mathrm{A}$ pena de prisão simples deve ser cumprida, sem rigor penitenciário, em estabelecimento especial ou seção especial de prisão comum, em regime semi-aberto ou aberto. 
$\int 1^{\circ} \mathrm{O}$ condenado a pena de prisão simples fica sempre separado dos condenados a pena de reclusão ou de detenção.

$\int 2^{\circ}$ O trabalho é facultativo, se a pena aplicada, não excede a quinze dias".

Para identificar qual regime será submetido o agente já condenado pela prática de um crime, deve-se observar o disposto no $\$ 3^{\circ}$, do artigo 33, do Código Penal.

\section{"Reclusão e detenção}

Art. 33 - A pena de reclusão deve ser cumprida em regime fechado, semi-aberto ou aberto. A de detenção, em regime semi-aberto, ou aberto, salvo necessidade de transferência a regime fechado.

$[\ldots] \rrbracket 2^{\mathbf{o}}-$ As penas privativas de liberdade deverão ser executadas em forma progressiva, segundo o mérito do condenado, observados os seguintes critérios e ressalvadas as hipóteses de transferência a regime mais rigoroso:

a) o condenado a pena superior a 8 (oito) anos deverá começar a cumpri-la em regime fechado;

b) o condenado não reincidente, cuja pena seja superior a 4 (quatro) anos e não exceda a 8 (oito), poderá, desde o princípio, cumpri-la em regime semiaberto;

c) o condenado não reincidente, cuja pena seja igual ou inferior a 4 (quatro) anos, poderá, desde o início, cumprila em regime aberto". Negrito nosso.

Quanto aos regimes, o fechado é considerado o mais grave pelo fato do condenado ficar sujeito a trabalho no horário diurno dentro do estabelecimento prisional ou ocupações anteriores a condenação quando compatível com a pena, sendo admitido o trabalho externo quando em serviços ou obras públicas, devendo ficar isolado durante o repouso noturno.

No semiaberto o sentenciado ficará sujeito a trabalho em colônia agrícola, indústria ou estabelecimento similar, durante o período diurno, sendo admitido trabalho externo, cursos supletivos profissionalizantes de segundo grau ou superior. Tanto o fechado como o semiaberto, ambos submeterão o condenado a exame criminológico de classificação no início da pena, com o intuito de individualizar da execução.

Já o regime aberto baseia-se na autodisciplina e senso de responsabilidade do condenado, o qual fora do estabelecimento 
prisional e sem vigilância, deverá trabalhar, frequentar curso ou exercer outra atividade autorizada, contudo, no período noturno e nos dias de folga deverão permanecer recolhidos. Havendo a possibilidade de regressão de regime, caso pratique crime doloso, se frustrar os fins os fins de execução ou se não pagar a multa cumulativamente aplicada.

As penas restritivas de direito, de acordo com o expresso no artigo 43 do Código Penal, são: prestação de serviços à comunidade, interdição temporária de direitos e limitação de fim de semana. Quando a prestação de serviço à comunidade, essa não pode ser utilizada como meio de exposição vexatória do condenado, pois não há de ser aviltante; a interdição temporária de direitos possui relação entre o ato praticado e a sua consequência, buscando atender às funções retributiva e preventiva das penas; já a limitação de fim de semana assim como o próprio nome dita, visa restringir à liberdade do condenado justamente aos fins de semana.

Essa modalidade de pena é espécie autônoma e em regra são aplicadas em substituição à pena privativa de liberdade, no entanto, deve-se observar o disposto no artigo 44 do diploma retro mencionado.

“Art. $44-$ As penas restritivas de direitos são autônomas e substituem as privativas de liberdade, quando:

I - aplicada pena privativa de liberdade inferior a um ano ou se o crime for culposo;
II - o réu não for reincidente;

III - a culpabilidade, os antecedentes, a conduta social e a personalidade do condenado, bem como os motivos e as circunstâncias indicarem que essa substituição seja suficiente.

Parágrafo único - Nos crimes culposos, a pena privativa de liberdade aplicada, igual ou superior a um ano, pode ser substituída por uma pena restritiva de direitos e multa ou por duas penas restritivas de direitos, exequíveis simultaneamente."

Assim, do mesmo modo que pode haver a substituição da privativa de liberdade para restritiva de direito, também de admite o inverso nos casos em que sobrevier condenação por outro crime a pena privativa de liberdade cuja execução não tenha sido suspensa e quando ocorrer $\mathrm{o}$ descumprimento injustificado da restrição imposta.

No que tange sob a pena de multa, essa consiste no pagamento ao fundo penitenciário da quantia fixada na sentença condenatória e calculada em dias-multa, com mínimo de 10 (dez) e máximo de 360 (trezentos e sessenta). O valor de dia-multa deve ser calculado pelo juiz não podendo ser inferior a um trigésimo do maior salário mínimo 
mensal, nem superior a cinco vezes o valor desse salário, o qual deve ser computado sob o valor vigente ao tempo da condenação. Esse valor da multa deverá ser atualizado quando da execução, pelos índices de correção monetária, devendo ser paga dentro de 10 (dez) dias após o trânsito em julgado da sentença, sendo admitido o pagamento parcelado desde que seja requerido e conforme suas circunstâncias.

Essa espécie dos gêneros da pena também possui autonomia pode ser cominada isoladamente, bem como cumulativamente.

Caso o condenado não venha a efetuar o pagamento da multa ou venha frustrar a sua execução, poderá haver a conversão a pena de multa para a de detenção, na qual cada dia multa corresponderá a um dia de detenção, desde não superior a um ano, havendo a revogação da conversão caso haja o pagamento da multa, podendo esse ser a qualquer tempo. Admitindo ainda a suspensão da execução da pena de multa caso o condenado sobrevenha a ter doença mental.

Ainda sob o não pagamento da multa Eugênio Pacelli e André Callegari (2017, p. 483) lecionam que:

"Se a multa não for paga, independentemente das condições econômicofinanceiras do condenado, ela será considerada dívida de valor, aplicando-se, então, a legislação pertinente à dívida ativa da Fazenda Pública, inclusive no que se refere às causas de interrupção e de suspensão do prazo prescricional. Os prazos prescricionais, no entanto, continuam sendo aqueles previstos na legislação penal (art. 114, CP)".

\subsection{Medida de segurança}

A medida de segurança é a espécie de sanção penal que possui carater preventivo e curativo, a qual visa que o condenado pela pratica de uma infração penal, o qual é inimputável ou semi-imputável e periculoso, não volte a cometer outro ato ilícito e receba tratamento adequado.

No ordenamento penal atual prevale o sistema vicariante, que admite apenas a aplicação de pena ou de medida de segurança, ao contrário do sistema duplo binário que vigorava antes da reforma de 1984, que permitia tanto a aplicação da pena e da medida de segurança.

O artigo penal disponibiliza duas especies de medidas de segurança, sendo a interdição hospitalar de custodia e tratamento psiquiátrico, ou na falta desde em outro estabelecimendo adequado, e a sujeição a tratamento ambulatorial.

Sob a ação penal, mesmo se tratando de inimputabel ou inimputavel, esse terá direito a ampla defesa e ao contraditorio, sendo permitido ao juiz aplicar-lhe medida de segurança apenas após a produção de prova e constatação da pratica do injusto. Porém, caso esteja presente alguma excludente de ilicitudo ou compravado a insuficiencia de prova, o juiz será obrigado a absolver o agente por falta de antijuridicidade, sem aplicar-lhe medida de segurança. 
Sob a conversão da pena em medida de segurança no curso da execução penal, Nucci (2017, p. 925) nos diz que:

"Preceitua o art. 183 da Lei de Execução Penal: "Quando, no curso da execução da pena privativa de liberdade, sobrevier doença mental ou perturbação da saúde mental, o Juiz, de ofício, a requerimento do Ministério Público, da Defensoria Pública ou da autoridade administrativa, poderá determinar a substituição da pena por medida de segurança".

É preciso distinguir duas hipóteses: a) se condenado sofrer de doença mental, não se tratando de enfermidade duradoura, deve ser aplicado o disposto no art. 41 do Código Penal, ou seja, transfere-se o sentenciado para hospital de custódia e tratamento psiquiátrico pelo tempo suficiente à sua cura. Não se trata de conversão da pena em medida de segurança, mas tão somente de providência provisória para cuidar da doença do condenado. Estando melhor, voltará a cumprir sua pena no presídio de onde saiu, desde que haja saldo remanescente; $b$ ) caso a doença mental tenha caráter duradouro, a transferência do condenado não deverá ser feita como providência transitória, mas sim definitiva. Por isso, cabe ao juiz converter a pena em medida de segurança, aplicando-se o disposto no art. 97 do Código Penal".

Segundo o disposto no Código Penal, a medida de segurança será por tempo indeterminado, até que por meio de perícia médica se constate a cessação da periculosidade do condenado, com prazo de mínimo de 1 (um) a 3 (três) anos. No entanto, a aplicação por tempo indeterminado ainda não é um tema pacificado no ramo do Direito Penal.

\subsection{Penas}

aplicáveis

$\operatorname{aos}$

\section{portadores de psicopatia}

O capítulo III do Código Penal disciplina sob a aplicação da pena, lencionando em seu artigo 59, sob a fixação da pena, veja-se:

$\begin{array}{lr}\text { "Art. } 59- & \text { O juiz, } \\ \text { atendendo } & \text { à } \\ \text { culpabilidade, } & \text { aos } \\ \text { antecedentes, à conduta } \\ \text { social, à personalidade do }\end{array}$


agente, aos motivos, às circunstâncias e consequências do crime, bem como ao comportamento da vítima, estabelecerá, conforme seja necessário e suficiente para reprovação e prevenção do crime:

I - as penas aplicáveis dentre as cominadas;

II - a quantidade de pena aplicável, dentro dos limites previstos;

III - o regime inicial de cumprimento da pena privativa de liberdade;

IV - a substituição da pena privativa da liberdade aplicada, por outra espécie de pena, se cabível”.

O artigo 26 do Código Penal, conforme já mencionado, tratará da isenção de pena aos inimputaveis, estabelecendo quem serão passiveis dessa aplicação e quais condição aceitaveis.

“Art. $26-$ É isento de pena o agente que, por doença mental ou desenvolvimento mental incompleto ou retardado, era, ao tempo da ação ou da omissão, inteiramente incapaz de entender o caráter ilícito do fato ou de determinar-se de acordo com esse entendimento".

Conforme entendimento do Superior Tribunal de Justiça, sob o julgamento de um recurso especial no que tange a interdição de um psicopata o qual julgou procedente, manifestou-se: “[...] A psicopatia está na zona fronteiriça entre a sanidade mental e a loucura, onde os instrumentos legais disponíveis mostram-se ineficientes, tanto para a proteção social como a própria garantia de vida digna aos sociopatas, razão pela qual deve ser buscar alternativas, dentro do arcabouço legal para, de um lado, não vulnerar as liberdades e direitos constitucionalmente assegurados a todos e, de outro turno, não deixar a sociedade refém de pessoas, hoje, incontroláveis nas suas ações, que tendem à recorrência criminosa. 5 . Tanto na hipótese do apenamento quanto na medida socioeducativa ontologicamente 
distintas, mas intrinsecamente iguais - a repressão do Estado traduzida no encarceramento ou na internação dos sociopatas criminosos, apenas postergam a questão quanto à exposição da sociedade e do próprio sociopata à violência produzida por ele mesmo, que provavelmente, $\quad \mathrm{em}$ algum outro momento, será replicada, pois na atual evolução das ciências médicas não há controle medicamentoso ou terapêutico para essas pessoa $[\ldots]$..."

Entende-se diante todo o exposto, bem como sob a ótica da corrente conservadora, sginificado etimologico da palavra psicopatia, do STJ e das caracteristicas e definições da psicopatia, o psicopata não possuie completa sanidade mental e possue resistencia em obedecer às regras impostas pela sociedade, tendo em vista as caracteristicas da sua personalidade.

Conforme dito acima e o constante no artigo 26, já citado anteriormente, será isento de pena aquele que por doença mental ao tempo da ação ou omissão não era inteiramente capaz de determinar-se de acordo com o entendimento do carater ilícito do fato. Assim, forçoso o reconhecimento do psicopata como agente passivel de tal isenção, tendo em vista que diante das caracteristicas da sua personalidade, circunstancia do fato e que dependendo do grau da doença, não é possivel esperar conduta diversa da ilícita por parte deste.

Em consonancia com o disposto, o meio de aplicação correto é a de medida de segurança, conforme o artigo 97, do Código Penal, veja-se:

\section{"Imposição da medida de segurança para inimputável}

Art. 97 - Se o agente for inimputável, o juiz determinará sua internação (art. 26). Se, todavia, o fato previsto como crime for punível com detenção, poderá o juiz submetê-lo a tratamento ambulatorial".

É cediço que é inútil a tentativa de reedução do portador de psicopatia, tal como a sua regeneração, tendo em vista a sua personalidade não agranger o carater ético, conclui-se assim que a aplicação de pena a esse individua será infrutifera e vil. Reforçando ainda mais a tese que acolhe como meio de aplicação correta a esses agentes a medida de segurança.

\section{CONSIDERAÇÕES FINAIS}

A psicopatia é desafiadora para todas as ciências que as norteiam e para o dereito não é diferente, ainda mais sob o meio de aplicação de pena. O presente trabalho defendeu que a psicopatia é uma doença mental, que afeta a condição psiquica daquele a possui, os quais em 
decorrência dessas condições devem ser punidos com aplicação de medida de segurança.

Tendo em vista a personalidade do psicopata, a aplicação de pena a esse indivíduo não terá êxito algum, acarretando apenas prejuizo ao judiciário, instabilidade a sociedade e aqueles a integram, bem como ao próprio individuo portador da psicopatia.

Nesse sentido, não basta apenas à aplicação de medida de segurança para aqueles que serão julgados, sendo necessária a identificação daqueles já inseridos no meio prisional por meio de condenação.

Para a implementação dessa medida é necessário à criação de mais hospitais de custódia ou outros estabelecimentos adequados para o tratamento desses individuos e um maior cuidado durante o processo penal e após a condenação para que haja identificação desses individuos, por meio de exames periciais e avaliação interdiciplinar tecnica.

\section{REFERÊNCIAS}

\section{AGÊNCIA SENADO. Psicopatia: transtorno} começa na infância ou começo da adolescência. [Acesso em: 19 de fevereiro de 2018]. Disponível em: http://abp.org.br/portal/clippingsis/exibCli pping/?clipping=11611.

ARAÚJO, Fabíola dos Santos. O Perfil do Criminoso Psicopata. [Acesso em: 19 de fevereiro de 2018]. Disponível em: http://www.conteudojuridico.com.br/artigo, o-perfil-do-criminoso-psicopata,32921.html.

BITENCOURT, Cezar Roberto. Tratado de Direito Penal: parte geral 1. 15.ed. São Paulo: Saraiva, 2010.

BRASIL. Código Penal. [Acesso em: 25 de novembro de 2017]. Disponível em: http://www.planalto.gov.br/ccivil 03/decret o-lei/Del2848compilado.htm.
BRASIL. Constituição (1988). Constituição da República Federativa do Brasil. [Acesso em: 25 de novembro de 2017]. Disponível em: http://www.planalto.gov.br/ccivil 03/consti tuicao/constituicaocompilado.htm.

BRASIL. Superior Tribunal de Justiça. [Acesso em: 25 de fevereiro de 2018]. Disponível em: https://sti.jusbrasil.com.br/jurisprudencia/2 5054791/recurso-especial-resp-1306687-mt2011-0244776-9-stj.

CAPEZ, Fernando. Curso de Direito Penal, volume 1, parte geral: arts. $1^{\circ}$ a 120.21 .ed. São Paulo: Saraiva, 2017.

CASOY, Ilana. Serial Killer Made in Brasil. Rio de Janeiro: Ediouro, 2009.

CASTRO, Isabel Medeiros de. Psicopatia e suas Consequências Jurídico-Penais. [Acesso em: 25 de novembro de 2017]. Disponível em: http://www3.pucrs.br/pucrs/files/uni/poa/ direito/graduacao/tcc/tcc2/trabalhos2012 1 Lisabel castro.pdf.

COLUNISTA PORTAL - EDUCAÇÃO. Erro de Proibição ou Erro sobre a Ilicitude do Fato. [Acesso em: 25 de novembro de 2017]. Disponível em: https://www.portaleducacao.com.br/conteu do/artigos/direito/erro-de-proibicao-ouerro-sobre-a-ilicitude-do-fato/15982.

CORSI, Éthore Conceição. Pena: origem, evolução, finalidade, aplicação no Brasil, sistemas prisionais e políticas públicas que melhorariam ou minimizariam a aplicação da pena. [Acesso em: $22 \mathrm{de}$ fevereiro de 2018]. Disponível em: http://www.ambitojuridico.com.br/site/?n link= revista artigos leitura\&artigo $\mathrm{id}=17376 \&$ revista caderno= 3#.

CUNHA, Rogério Sanches. Manual de Direito Penal: parte geral. $3^{\circ}$ ed. Salvador: Editora JusPodivm, 2015.

DSM-5. Manual Diagnóstico e Estatístico de Transtornos Mentais. [Acesso em: 23 de fevereiro de 2018]. Disponível em: https://blogs.sapo.pt/cloud/file/b37dfc58aa d8cd477904b9bb2ba8a75b/obaudoeducador L2015/DSM \%20V.pdf.

ESTEFAM, André. Direito Penal, 1: parte geral. $3^{\circ}$ ed. São Paulo: Saraiva, 2013. 
HARE, Robert D. Sem consciência: o mundo perturbador dos psicopatas que vivem entre nos. Porto Alegre: Editora Artmed, 2013.

HUSS, Matthew T. Psicologia Forense: pesquisa, prática clínica e aplicações. Porto Alegre: Artmed, 2011.

JESUS, Damásio E. de. Direito Penal, volume 1: parte geral. 29.ed. São Paulo: Saraiva, 2008.

MIRABETE, Julio Fabbrini. Manual de Direito Penal - Parte Geral. 22.ed. São Paulo: Atlas, 2005.

MIRABETE, Julio Fabbrini. Manual de Direito Penal, volume 1: parte geral. 25.ed. São Paulo: Atlas, 2009.

MORANA, Hilda C. P.; STONE, Michael H.; FILHO, Elias Abdalla. Transtornos de Personalidade, Psicopatia e Serial Killers. [Acesso em: 24 de fevereiro de 2018]. Disponível em: http://www.scielo.br/pdf/rbp/v28s2/04.pdf

NADER, Ana Carolina Marchetti. A Possibilidade da Aplicação de Medida de Segurança ao Psicopata. [Acesso em: 05 de outubro de 2017]. Disponível em: http://www.clubjus.com.br/document/2857 $\underline{57835}$.

NUCCI, Guilherme de Souza. Curso de Direito Penal: parte geral: arts. $\mathbf{1}^{\mathrm{o}}$ a $\mathbf{1 2 0}$ do Código Penal. Rio de Janeiro: Forense, 2017.

OMS. Classificação Estatística Internacional de Doenças e Problemas Relacionados A Saúde: Cid-10. Vol.1, Editora: Edusp, 2014.

PALHARES, Diego de Oliveira; CUNHA, Marcus Vinícius Ribeiro. O Psicopata e o Direito Penal Brasileiro. Qual a sanção penal adequada? [Acesso em: 22 de fevereiro de 2018]. Disponível em: http://www.fucamp.edu.br/editora/index.ph $\mathrm{p} / \mathrm{praxis} /$ article/view/255/214.
PACELLI, Eugênio; CALLEGARI, André. Manual de Direito Penal: parte geral. 3.ed. São Paulo: Atlas, 2017.

REIS, Alan. Imputabilidade Penal: Uma Abordagem Contemporânea. [Acesso em: 26 de novembro de 2017]. Disponível em: https://advalanreis.jusbrasil.com.br/artigos/ 235061925/imputabilidade-penal-umaabordagem-contemporanea.

REZENDE, Bruna Falco de. Personalidade Psicopática. [Acesso em: 23 de fevereiro de 2018] Disponível em: http://webcache.googleusercontent.com/sea rch?q=cache:http://www.unipac.br/site/bb/ teses/teses-

7574dbfdc05a0a6d7bf6be931322f26f.pdf\&g ws $r d=$ cr\&dcr $=0 \&$ ei $=$ ouaBWoqEFO $6 f$ Qb Vp7WYDg.

SANTOS, Gabriela Lopes dos; ANDRADE, Alcilene Lopes de Amorim. Da Imputabilidade do Psicopata. [Acesso em: 21 de fevereiro de 2018]. Disponível: https://gabrielalopesarteepoesia.files.wordpr ess.com $/ 2017 / 07 /$ da imputabilidade do psi copata.pdf.

SILVA, Ana Beatriz Barbosa. Mentes Perigosas - O Psicopata Mora ao Lado. Ed. De bolso. Rio de Janeiro: Objetiva, 2010.

SILVA, Claudia. O Psicopata e a Política Criminal Brasileira. [Acesso em: 05 de outubro de 2017]. Disponível em: https://www.jurisway.org.br/v2/dhall.asp?id $\mathrm{dh}=9440$.

SMANIO, Gianpaolo Poggio; FABRET'TI, Humberto Barrionuevo. Introdução ao Direito Penal: criminologia, princípios e cidadania. São Paulo: Atlas, 2010.

VALLIM, Liliane Granemann Cardoso. Psicopatia. [Acesso em: 21 de fevereiro de 2018]. Disponível em: https://blogdapsicoblog.wordpress.com/201 6/10/18/psicopatia-2/. 